\title{
QM Study on the Mechanism of Carbonic Anhydrase II Inhibition with Glycosylcoumarin as Non-Zinc Mediated Inhibitors from Thermodynamic View Point
}

\author{
Mina Ghiasi* and Mina Seifi
}

Department of Chemistry, Faculty of Physics \& Chemistry, Alzahra University, 19835-389, Vanak, Tehran, Iran

\begin{abstract}
Carbonic anhydrase is an enzyme which has the zinc as the metallic part of it. This enzyme catalyzes the reversible reaction of turning carbon dioxide into bicarbonate. In this research the mechanism of inhibition a new class of inhibitor of this enzyme, glycosyl coumarin has been modeled using the density functional theory (DFT). First, the most constant confirmer of this four coumarin sugar derivatives which includes galactose, mannose, ribose and glucose has been selected and then they had been interacted as inhibitor with CA (II) enzyme's active site. In further for showing the effect of sugar in these molecules, coumarin itself had been chosen as inhibitor and the inhibitory effect is surveyed. All calculations have been done by density functional theory in level of B3LYP with basic set 6-31G* and with Minnesota function M06 with basic set $6-31+G^{*}$. Thermodynamic functions like enthalpy of formation, entropy of formation and Gibbs free energy for CA-inhibitor have been computed. The results indicate that the reaction among these groups of inhibitors and Carbonic anhydrase is not of the type of direct and syndetic but the enzyme is deactivated with space effect and addition to this, the computed thermodynamic functions show that although this coumarin sugar derives have deterrence in the range of micro molar but, coumarin without sugar is a stronger deterrence for CA II. Finally, the interaction between the most constant confirmer (galactose coumarin) is surveyed as the best deterrence using the explicit solvent method.
\end{abstract}

Keywords: Carbonic Anhydrase, glycosylcoumarin, inhibition mechanism, Density functional theory, explicit solvent method.

\section{INTRODUCTION}

Carbonic anhydrase (CA) is a ubiquitous zinc enzyme that accelerates the reversible hydration of $\mathrm{CO} 2$ into bicarbonate. There are five groups $(\alpha, \beta, \gamma, \delta$, $\varepsilon)$ of genetic distinct Carbonic anhydrase enzymes in the whole phylogenetic tree. The first genetic group is alpha Carbonic anhydrases ( $\alpha \mathrm{CAs}$ ) which are found in vertebrates, single cells, alga, cytoplasm of green plants and some of the bacterias. All the Carbonic anhydrases are metalloenzymes. Alpha Carbonic anhydrases use zinc $(\mathrm{Zn}(\mathrm{II}))$ in their active site [1-11]. The active site of all these enzymes show a similar topology. The three remained histidine, a water molecule / hydroxide ion are tetrahedrally coordinated into zinc ion [12]. Carbonic anhydrase is inhibited by an extended numbers of different inhibitors and often using their anion [13], for instance: metal complexing anion, sulfonamides, sulfamides, phenols and polyamines that bind to the metal ion through the enzyme active center or are anchored to the water molecule coordinated to the metal ion[14,15]. These inhibitors function as CA I and II strong inhibitors [1618].

\footnotetext{
*Address correspondence to this author at the Department of Chemistry, Faculty of Physics \& Chemistry, Alzahra University, 19835-389, Vanak, Tehran, Iran; Tel: +9821 88044051-9(2602); Fax: +9821 88041344; E-mail: ghiasi@alzahra.ac.ir,mina.70693@yahoo.com
}

In the recent years a new group of CA inhibitors (coumarin and its derivatives) have been reported[1921] that inhibit CA isoforms IX, XII, and XIII, Figure 1. The mechanism of coumarins is different from all the known inhibitors. In fact, many of the known inhibitors connect directly to zinc ion using the active site but coumarins occupy the entrance space of the enzyme's active site in which it does not make any connection with three remained histidine and water molecule [2224]. Scheme 1 presents the proposed inhibition mechanism of CAll by galactose coumarin, leading to cis- or trans-2-hydroxy-cinamic acid. The main problem of classic carbonic anhydrase inhibitors is their lack of selectivity. Recently, some coumarin sugar derivatives with strong inhibition have been discovered which they are related to CA XII and CA IX isoforms that Prevent the growth of primary tumors and metastasis. These sugar derivatives have selectivity manner and they are stronger inhibitors for CA XII and CA IX [12]. This research is going to study the mechanism of the inhibition of the new group of the inhibitors (coumarin sugar derivatives) with active form of CA II. According to previous study the presence of the sugar moieties in glycosidic sulfonamide carbonic anhydrase II inhibitors show less effective inhibition [25]. Figure 2 shows the derivatives of coumarin. 


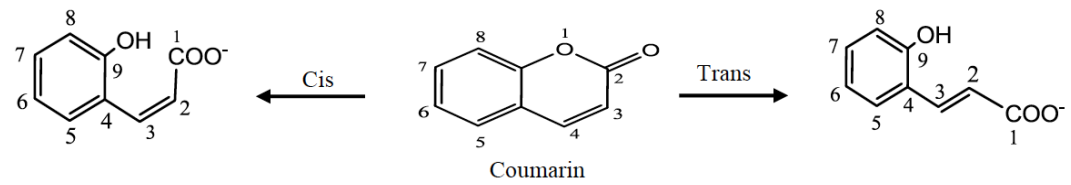

Figure 1: Presentation of coumarin molecule and its hydrolysis product, cis- and trans-2-hydroxycinnamic acid with numbering for key atoms.
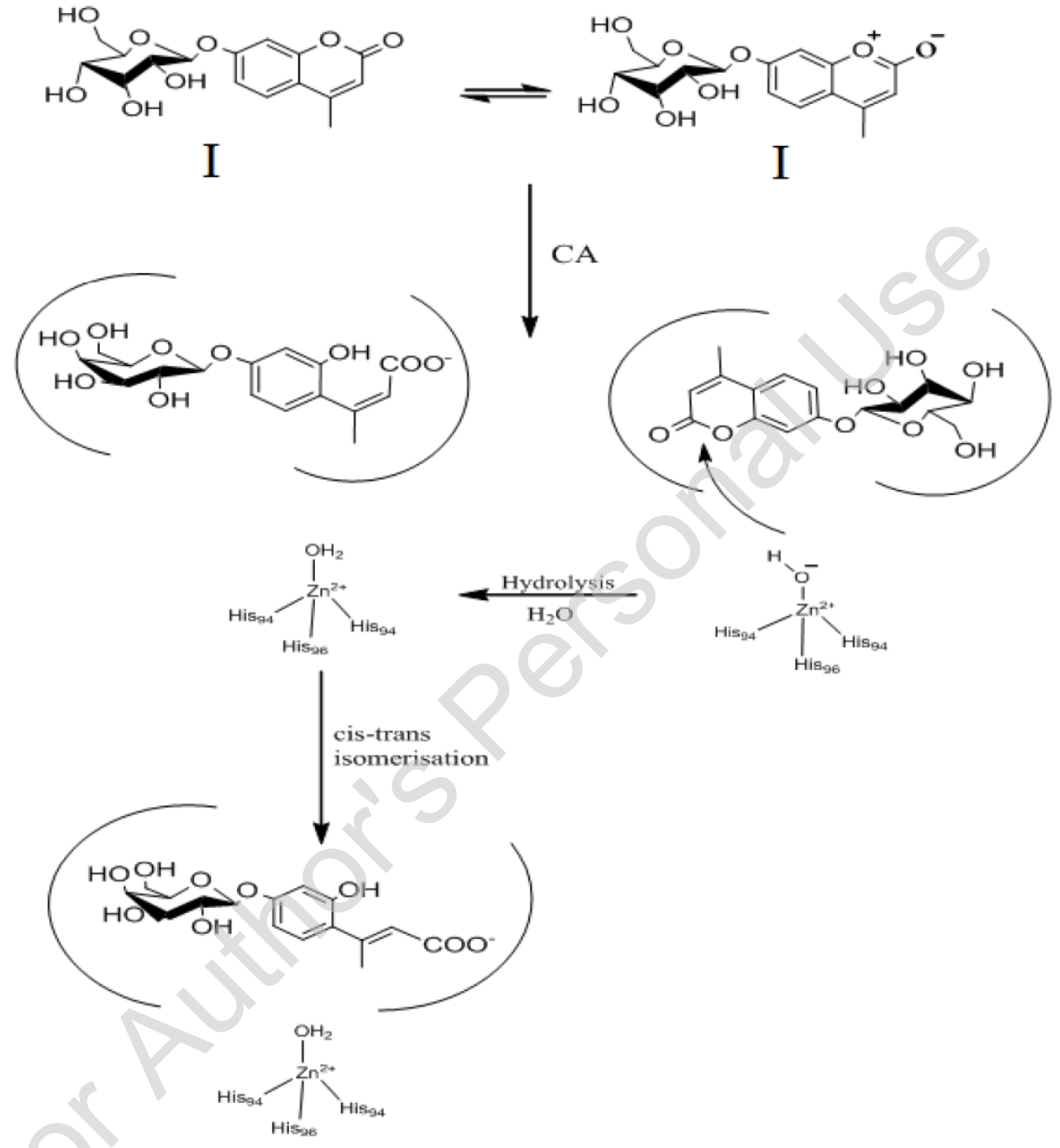

Scheme 1: Proposed inhibition mechanism of CAll by galactose coumarin that leading to cis/trans-2-hydroxy cinnamic acid.

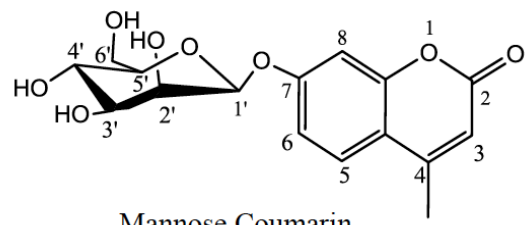<smiles>Cc1cc(=O)oc2cc(OC3O[C@H](O)[C@@H](O)[C@@H](O)[C@@H]3O)ccc12</smiles><smiles>Cc1cc(=O)oc2cc(OC3O[C@H](O)[C@@H](O)[C@@H](O)[C@H]3O)ccc12</smiles>

Glucose Coumarin

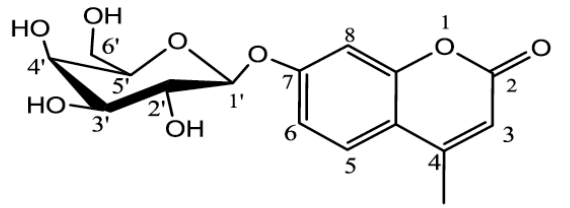

Galactose Coumarin

Figure 2: Presentation of 7-glycosyl-4-methyl coumarin with numbering for key atoms. 


\section{COMPUTATIONAL SCHEME}

\subsection{Ab Initio Calculations}

All the calculations have been done via the software Gaussian 2009 [26] and guess view application [27]. The geometry of the active and inactive form of active site of Carbonic anhydrase, inhibitors and their hydrolyzed form (cis and trans) and the complex between inhibitors and Carbonic anhydrase is fully optimized by DFT methods [28]. All the calculations with no symmetry constrains have been carried out at two levels of DFT methods to compute the energy and geometrical parameters:

1. $6-31 G^{*}$ using the popular B3LYP level of theory that consists of hybrid Becke-Hartree-Fock exchange and Lee-Yang-Parr correlation functional with non-local correction [29].

2. 6-31+ $G^{*}$ basis set with M06 functional which has been introduced recently as hybrid metaGGA (generalized gradient approximation) exchange functional correlation [30].

To verify the optimized geometry related to a local minimum and the absence of delusive frequencies, the harmonic vibrational frequencies has been computed. Moreover, the thermodynamic properties of all the substances is obtained by computing the frequency at $298.15 \mathrm{k}$ and 1.0 atmosphere pressure. All the reported enthalpies were modified under consideration of Zero Point Energy (ZPE). Solvent effect is done by explicit solvent procedure to consider the water molecule. By defining the rotations angles as $\mathrm{O}_{5}-\mathrm{C}_{5}-\mathrm{C}_{6}-\mathrm{O}_{6}, \mathrm{C}_{5}-$ $\mathrm{C}_{6}-\mathrm{O}_{6}-\mathrm{H}$ and $\mathrm{H}_{1}-\mathrm{C}_{1}-\mathrm{O}-\mathrm{C}$, the angles' scan has been done on the geometrical parameters with the step $5^{\circ}$ and then the geometry has been optimized without any limitation around every potential minimum.

\subsection{Calculation of Thermodynamic Functions}

All the thermodynamic functions that are reported in this study, have been obtained by computing the frequency at $298.15 \mathrm{k}$ and 1.0 atmosphere pressure. The total enthalpies of the studied species at the $T$ temperature have been estimated usually by equation 1 [31-33].

$\mathrm{H}(\mathrm{x})=\mathrm{E}_{0}+\mathrm{ZPE}+\mathrm{E}_{\text {trans }}+\mathrm{E}_{\mathrm{vib}}+\mathrm{E}_{\mathrm{rot}}+\mathrm{RT}$

Which $E_{0}$ is the final electrical energy, ZPE is the abbreviation of zero point energy, $E_{\text {trans }}, E_{\text {vib }}$ and $E_{\text {rot }}$ are the representation of transition, rotation and vibration in enthalpy and finally $\mathrm{RT}$ represent the term pv-work which is added to change the energy into enthalpy. The equation of changing the enthalpy of reaction goes like this:

$\Delta \mathrm{H}^{\circ}{ }_{\mathrm{r}}=\left[\mathrm{H}^{\circ}\right.$ product $]-\left[\mathrm{H}^{\circ}\right.$ reactant $]$

And also changing the entropy of reaction is like what follows:

$\Delta \mathrm{S}_{\mathrm{r}}^{\circ}=\left[\mathrm{S}_{\text {product }}^{\circ}\right]-\left[\mathrm{S}^{\circ}{ }_{\text {reactant }}\right]$

Base on the thermodynamic equation, $\Delta \mathrm{G}=\Delta \mathrm{H}$ $\mathrm{T} \Delta \mathrm{S}$, Gibbs free energy change of the reaction $\left(\Delta \mathrm{G}_{\mathrm{r}}^{\circ}\right)$ can be computed which it is a measure of progress and Spontaneity of the reaction.

\section{RESULTS AND DISCUSSION}

3.1. Geometry Optimization of the Carbonic Anhydrase II Active Center in the Active and Inactive Forms, $\left[\mathrm{EZn}^{2+}-\mathrm{OH}^{-}\right]$and $\left[\mathrm{EZn}^{2+}-\mathrm{OH}_{2}\right]$

The model consists of a zinc cation which is located at the bottom of the conical active center which is bonded to $\mathrm{H}_{2} \mathrm{O}$ (in inactive form) or $\mathrm{OH}^{-}$(in active form) group, three imidazole rings belonging to the three remained histidine, His 94 , His 96 and His 119 which they all can be seen in the Figure 3. Structure of the active form of carbonic anhydrase II (ACA II) and the inactive form (ICA II) can be fully optimized at M06/6$31+G^{*}$ and $B 3 L Y P / 6-31 G^{*}$ without any Symmetric constraint.

Figure 3 shows the optimized structure and some structural details of ACA II in gas phase. The average distance between $\mathrm{Zn}^{2+}$ and the atom $\mathrm{N}$ in histidine in the both methods B3LYP and M06 is $2.04 \AA$.

\subsection{Geometry Optimization and Conformational Search of Inhibitors}

Since the most important angle in sugars is the dihedral angle in and around anomeric carbon and also the spot where glycosidic bond is made, Figure 4. Therefore the structural search plays an important role in this study. For all the inhibitors which include galactose, mannose, glucose and ribose coumarin, to find the most stable conformers, the dihedral angles $(\omega$ $\left.=\mathrm{O}^{\prime}-\mathrm{C} 5^{\prime}-\mathrm{C} 6^{\prime}-\mathrm{O} 6^{\prime}\right),\left(\theta=\mathrm{C} 5^{\prime}-\mathrm{C}^{\prime}-\mathrm{O} 6^{\prime}-\mathrm{H}\right)$ and $(\varphi=$ $\left.\mathrm{H} 1^{\prime}-\mathrm{C} 1^{\prime}-\mathrm{O}-\mathrm{C} 7\right)$ from $0^{\circ}$ to $360^{\circ}$ with the step of $5^{\circ}$ were scanned. Assuming that only the structures with the energy difference of $5-10 \mathrm{kcal} / \mathrm{mol}$ can be present at the room temperature, for all the four inhibitors only 

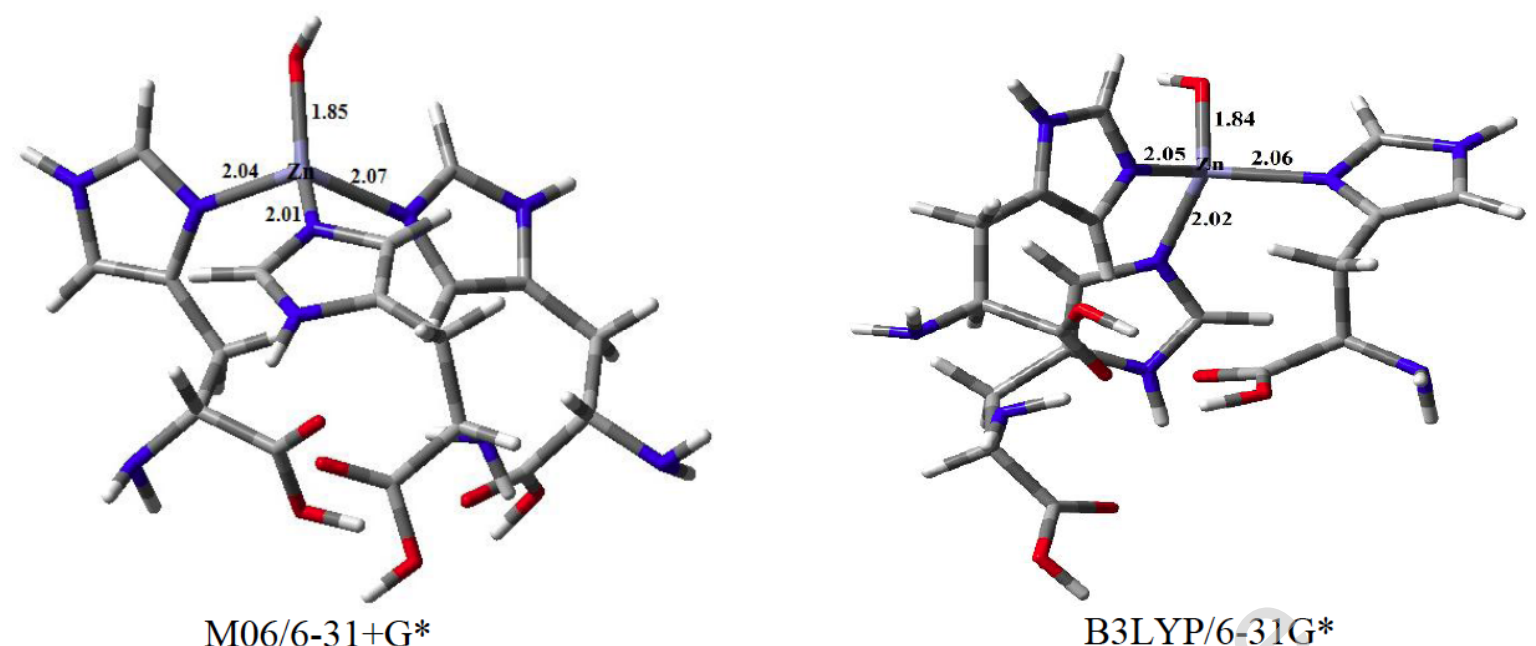

B3LYP/6-31G*

Figure 3: Optimized structure of the native CA II active site enzyme in the gas phase by using $B 3 L Y P / 6-31 G^{*}$ and $M 06 / 6-31+G^{*}$ methods. Distances are based on $\AA$.

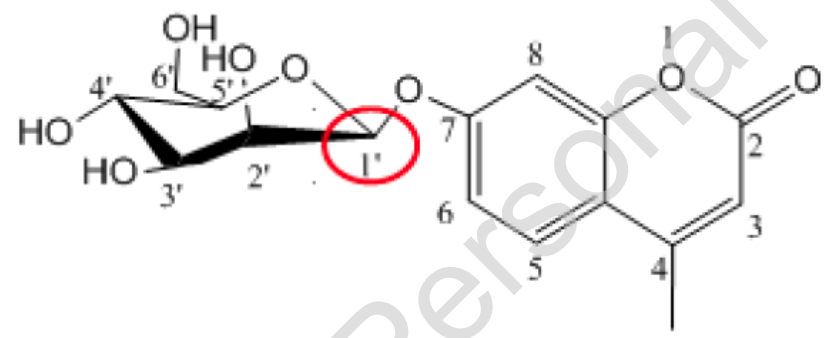

Figure 4: carbon anomeric's location.
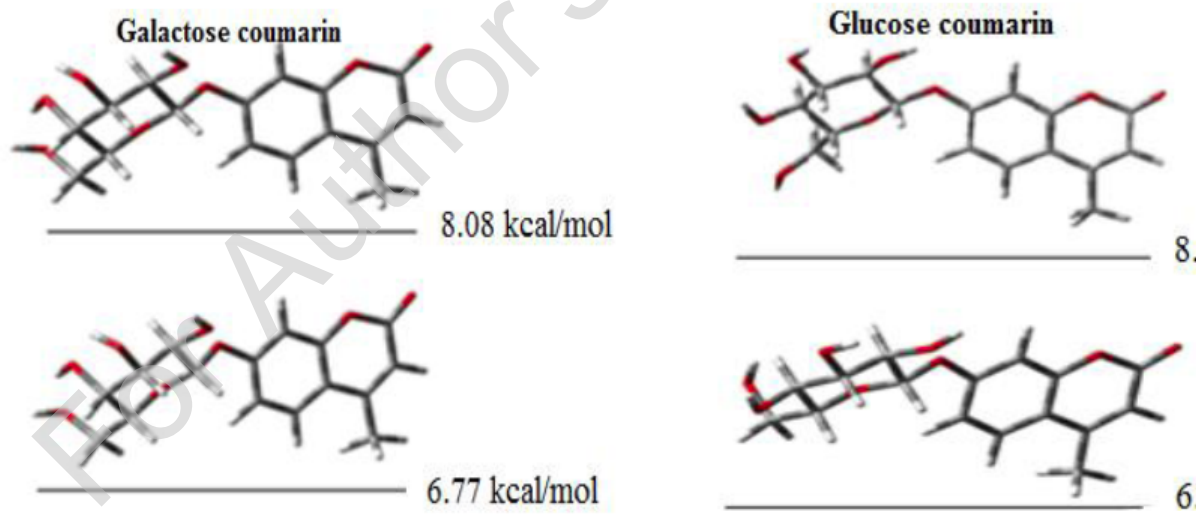

$8.59 \mathrm{kcal} / \mathrm{mol}$

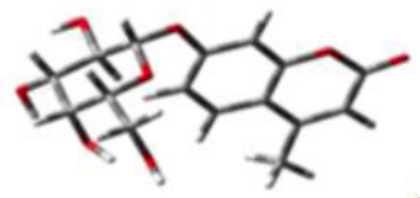

$5.07 \mathrm{kcal} / \mathrm{mol}$

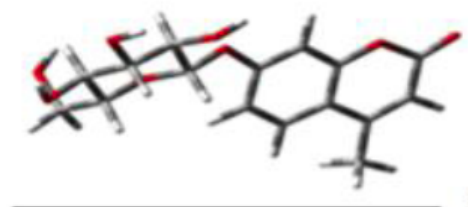

$6.8 \mathrm{kcal} / \mathrm{mol}$
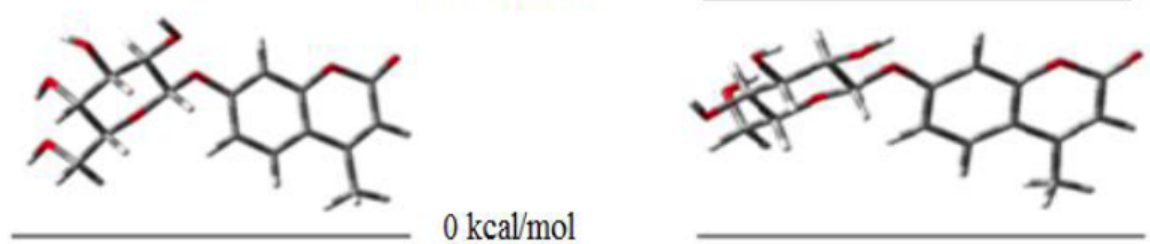

$5.39 \mathrm{kcal} / \mathrm{mol}$

$0 \mathrm{kcal} / \mathrm{mol}$

$0 \mathrm{kcal} / \mathrm{mol}$

Figure 5: Energy difference of the conformers of the glycosyl coumarin derivatives. 


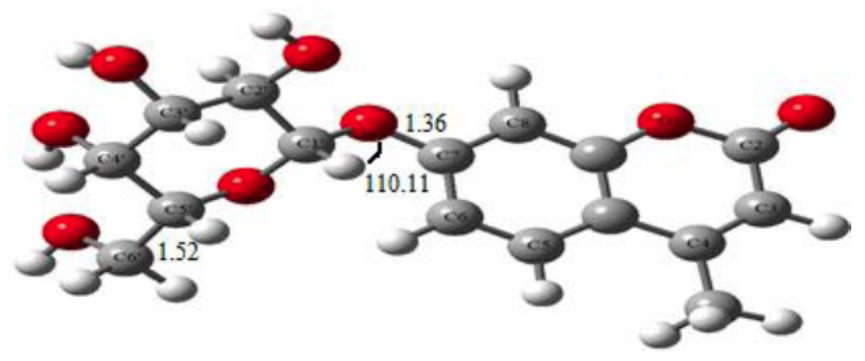

Galactose Coumarin



Ribose Coumarin

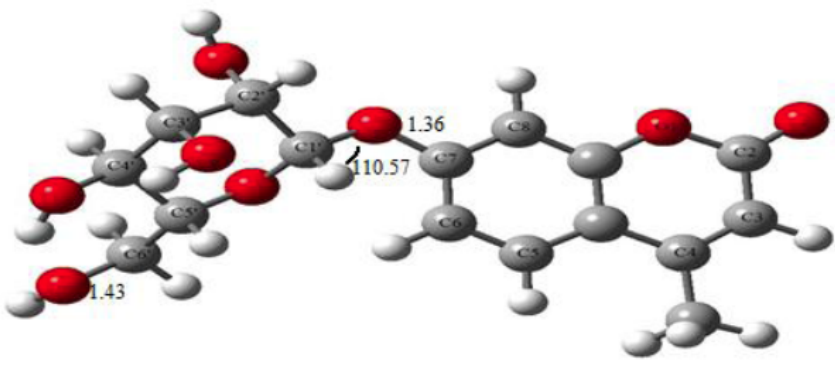

Mannose Coumarin

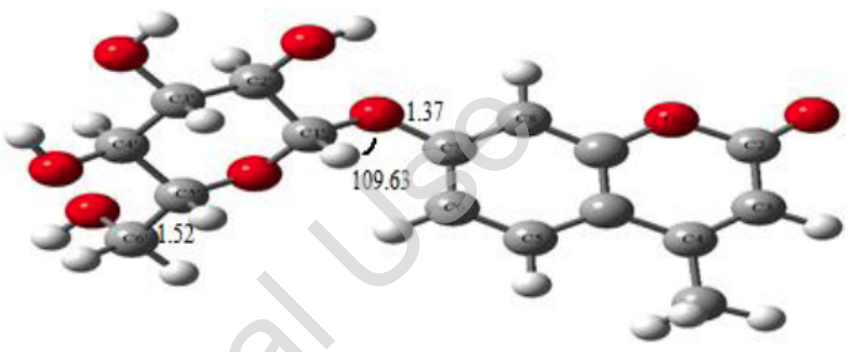

Glucose Coumarin

Figure 6: Presentation of optimized geometry of galactose, mannose, ribose and glucose coumarin derivatives at the B3lyp/6$31 \mathrm{G}^{*}$ method in gas phase.

one conformer was found, Figure 5. The most stable conformer of inhibitors is presented in Figure 6.

\subsection{Interaction between the Active Site of the Native CA II and Inhibitors}

As we can see in the Scheme 1, the inhibitor is placed in a space pocket close to the active form of the enzyme and unlike the other inhibitors, it doesn't make any interaction with zinc ion.

At the presence of the water molecule which hydrolyzes the enzyme and the inhibitor, the interaction goes on till the coumarin's inhibitor ring is opened and the both isomers, cis and trans are made, meanwhile hydroxyl enzyme group will turn to $\mathrm{H}_{2} \mathrm{O}$ which it will inactive carbonic anhydrase enzyme. There's a notable point in this interaction which it is approaching the inhibitor to enzyme and its effect of inactivation on it only based on the space effect and in this interaction, the inhibitor does not make any connection with the active center of enzyme.

In order to study the interaction of coumarin and carbonic anhydrase enzyme, first the reactants such as inhibitor, the active form of the enzyme and water molecule were separately and independently optimized and then all three molecules approaches each other so they can have space interaction, again these three groups of molecules were optimized at an approximate distance of $2-3 A^{\circ}$. finally, the products including cis and trans isomers of inhibitors and the inactive form of enzyme has been optimized. The results indicate that cis isomer is more constant about 27.99, 4.4, 24.04 and 31.13 than trans isomer at galactose, mannose, ribose and glucose coumarin respectivly. This stability comes from the internal hydrogen bond between carbonyl oxygen atom and hydroxyl hydrogen atom in cis isomer. The optimized structures and also energy stability through the reaction's pathway of all four inhibitors displayed in the Figure 7.

The energy barrier difference between reactions and products for the total reaction is calculated according to equation 4 and is about 132.54, 220.6, 137.85 and $130.45 \mathrm{kcal} / \mathrm{mol}$ for the cis isomer of galactose, mannose, ribose and glucose coumarin derivatives respectively in the B3LYP/6-31G* method.

$\Delta E=\left(E_{\text {int. }}+E_{I C A}\right)-\left(E_{A C A}+E_{i n h}\right)$

$E_{\text {int }}, E_{I C A}, E_{A C A}$ and $E_{\text {inh }}$ in order refer to the total calculated energy of cis or trans intermediate isomer, inactive and active form of CA II and inhibitor molecule respectively. To survey the role of sugar moiety in inhibition mechanism, we chose coumarin without sugar and then repeated all the calculations for this inhibitor, Figure 8. For all the five inhibitors, the energy 


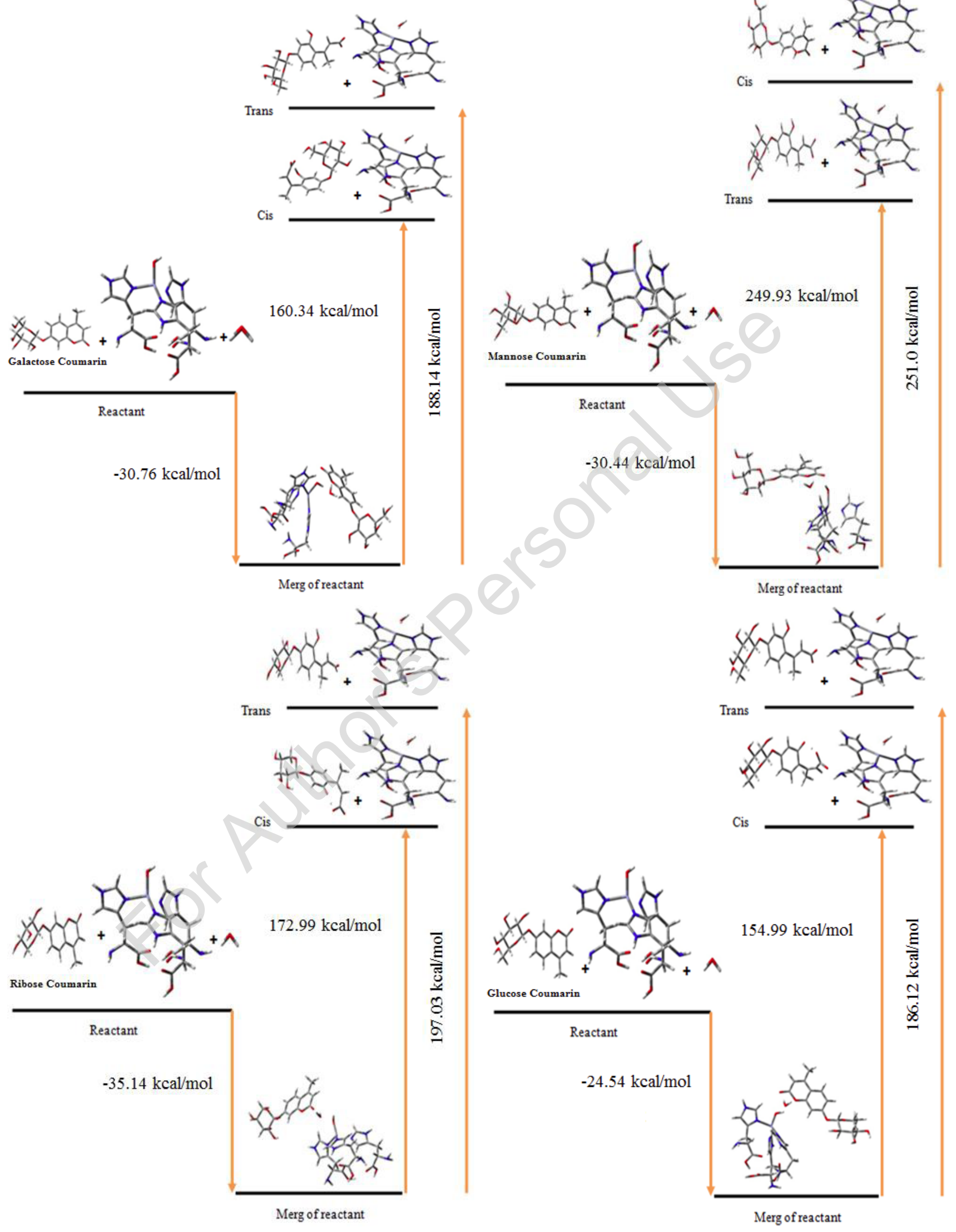

Figure 7: The optimized geometry and also energy stability through the reaction's pathway by galactose, mannose, ribose and glucose coumarin derivatives in the presence of one water molecule. 


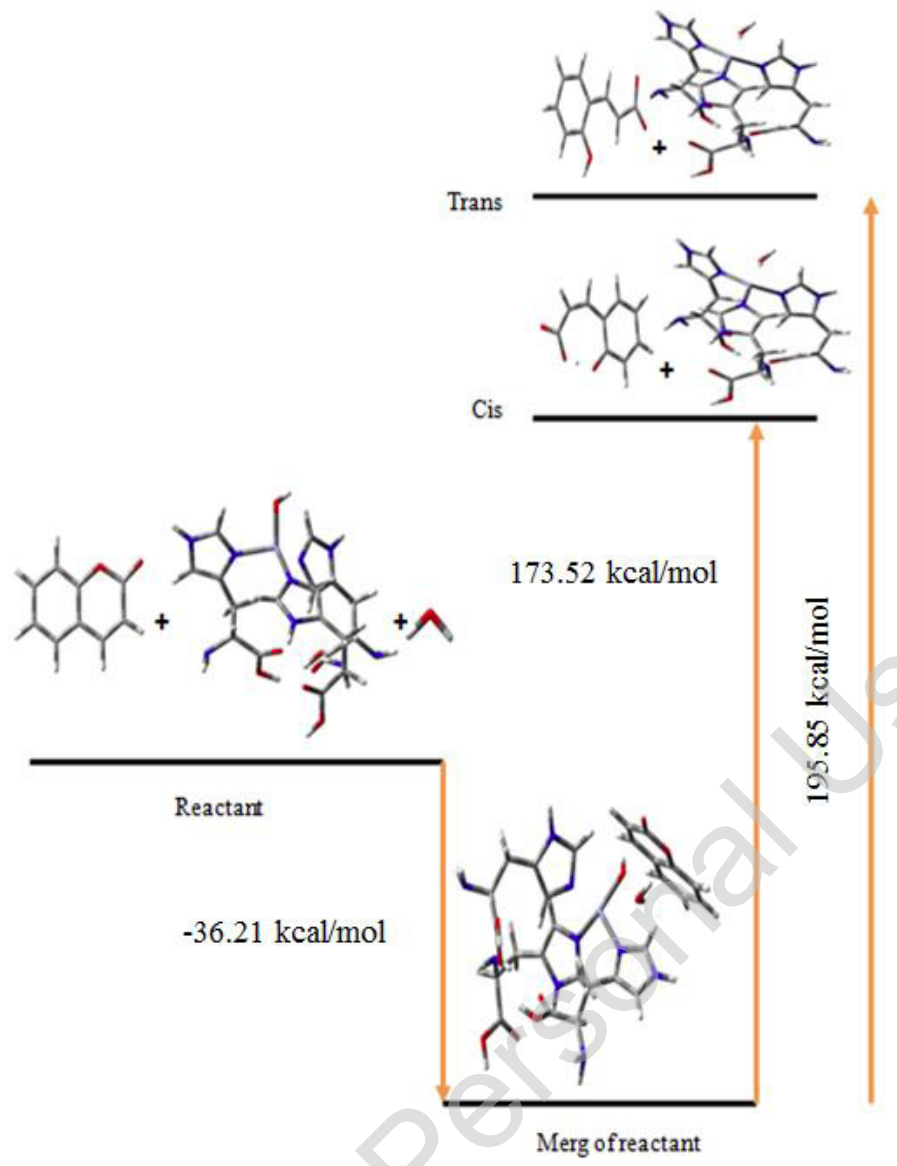

Figure 8: The optimized geometry of modeled systems in inhibition mechanism of CA II by coumarin in the presence of one water molecule.

Table 1: Thermochemistry of the reaction between five inhibitors and CA II calculated at B3LYP/6-31G* and M06/6$31+G^{*}$ methods. $\Delta E_{\text {tot }}$ is the reaction energy with the zero point energies included. Note that the conversion energy change values are in $\mathrm{kcal} / \mathrm{mol}$ and the entropy change values are in $\mathrm{cal} / \mathrm{mol}$

\begin{tabular}{|c|c|c|c|c|c|c|c|c|}
\hline Inhibitor & Isomer & \multicolumn{4}{|c|}{ B3LYP/6-31G* } & \multicolumn{3}{|c|}{$M 06 / 6-31+G^{*}$} \\
\hline $\begin{array}{l}\text { Galactos } \\
\text { Coumarin }\end{array}$ & Trans & 160.53 & 159.95 & 168.85 & -29.85 & 151.36 & 150.73 & 159.63 \\
\hline $\begin{array}{l}\text { Glocose } \\
\text { Coumarin }\end{array}$ & Cis & 130.45 & 129.87 & 142.65 & -42.86 & 128.45 & 127.87 & 140.65 \\
\hline \multirow{2}{*}{$\begin{array}{l}\text { Ribose } \\
\text { Coumarin }\end{array}$} & Cis & 137.85 & 137.27 & 150.05 & -42.86 & 135.29 & 134.71 & 147.49 \\
\hline & Trans & 161.89 & 161.31 & 170.21 & -29.85 & 155.18 & 154.6 & 163.5 \\
\hline \multirow{2}{*}{$\begin{array}{l}\text { Mannose } \\
\text { Coumarin }\end{array}$} & Cis & 220.6 & 219.48 & 232.26 & -42.86 & 229.23 & 228.65 & 241.43 \\
\hline & Trans & 219.49 & 218.91 & 227.81 & -29.85 & 231.55 & 230.97 & 239.87 \\
\hline
\end{tabular}

difference $\left(\Delta \mathrm{E}_{\mathrm{rxn}}\right)$ and all thermodynamic data for the reaction, including enthalpies $\left(\Delta \mathrm{H}^{\circ}{ }_{\mathrm{rxn}}\right)$ and Gibbs free energies $\left(\Delta \mathrm{G}^{\circ}{ }_{\mathrm{rxn}}\right)$ were computed at both levels M06/6-
$31+G^{*}$ and $B 3 L Y P / 6-31 G^{*}$. The result can be seen in the Table 1. $\Delta G^{\circ}$ rxn values indicate that sugar moiety's existence does not enhance coumarin's inhibition 


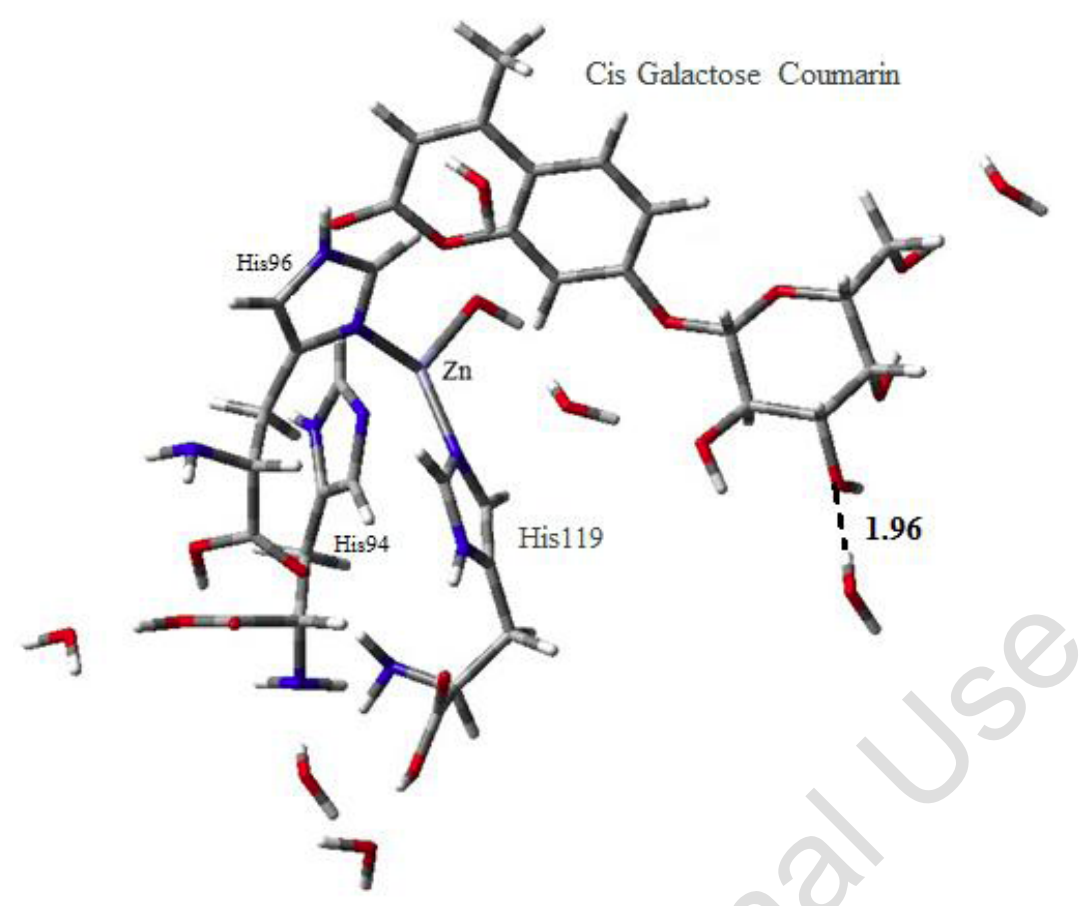

Figure 9: The optimized geometry of [ICA II/cis-galacto 2-hydroxy cinnamic acid] in the presence of six water molecules; Bond length is given in $\AA$.

Table 2: Thermochemistry of the reaction between galactose coumarin as the most effectiove inhibitor and CA II active site calculated at B3LYP/6-31G* method in the presence of six water molecules. $\Delta E_{\text {tot }}$ is the reaction energy with the zero point energies included

\begin{tabular}{|c|c|c|c|}
\hline$/ \mathbf{k c a l} . \mathrm{mol}^{-1}$ & $\Delta \mathrm{E}_{\mathrm{rxn}}^{\text {tot }}$ & $\Delta \mathbf{H}_{\mathrm{rxn}}^{\circ}$ & $\Delta \mathbf{G}^{\circ}{ }_{\mathrm{rxn}}$ \\
\hline \hline Cis isomer & -28.31 & -28.89 & -19.99 \\
\hline
\end{tabular}

power for the four CA Ils inhibitor and even in some cases like mannose coumarin, it decreases its power dramatically which we noticed this point at the previous experiments [23]. Base on the reported results in the Table 1, we can predict the inhibition power of these four sugar coumarins derivatives base on the $\Delta G$ values which it is: galactose coumarin $>$ glucose coumarin > ribose coumarin > mannose coumarin, therefore the tendency of galactose coumarin toward the CA II is more than the other studied derivatives.

The computed enthalpy values of all the inhibitors indicate that the reaction between the inhibitors and the active site of CA II is endothermic and we should notice that these results are obtained for gas phase and for only one water molecule so probably by considering the water molecule, the results will dramatically change which we will investigate it later.

\subsection{The Explicit Solvent Effect}

To investigate the solvent effect and water molecule's role in this study, explicit solvent method has been used. In this method six water molecule have been optimized and then they were arranged around the optimized structure of the reactant's merge. Since galactose coumarin was the strongest derive, solvent effect was checked for inhibitor, Figure 9. Table 2 shows the thermochemical functions of galactose coumarin's reaction with the active form of carbonic anhydrase II In the presence of six water molecule. Thermodynamic functions were computed only for the most stable isomer (cis isomer). The results of the calculations indicate that, by adding six water molecules, the reaction got more stable by 28.31 $\mathrm{kcal} / \mathrm{mol}$. The negative values of the thermodynamic functions for the interaction between active form of CA II and 7-galacto inhibitor shows that the reaction is exothermic and spontaneous.

\section{CONCLUSION}

In this research in order to make a theoretical study about the inhibition effect of a new group of inhibitors (coumarin and its sugar derivatives) on carbonic 
anhydrase II enzyme, quantum Computing and two levels of DFT methods in gas phase and explicit solvent have been used. First coumarin molecule and its sugar derivatives were optimized in gas phase and then their effect was investigated on the optimized active form of carbonic anhydrase enzyme. The presence of one water molecule is necessary to do the hydrolysis in the reaction. By doing this reaction, carbonic anhydrase becomes inactive and the inhibitor molecule opens and leads to form the isomers cis or trans. Energy difference between reactants and intermediate and products level is mean that the reaction is endothermic. Due to the high absorption rate of energy in gas phase, solvent effect with explicit method has been done for the most powerful inhibitor, galactose, which led to decrease thermodynamics parameters so the reaction can be done at the body temperature Spontaneously and it is exothermic. It is notable to say that these inhibitors are solved in water which it is an advantage for clinical usage of these inhibitors.

\section{ACKNOWLEDGEMENTS}

The authors gratefully acknowledge financial support from the research council of Alzahra University.

\section{REFERENCES}

[1] Supuran CT. Carbonic anhydrase inhibition with natural products: novel chemotypes and inhibition mechanisms. Mol Divers 2011; 15: 305-16.

https://doi.org/10.1007/s11030-010-9271-4

[2] Supuran CT. Carbonic anhydrases: novel therapeutic applications for inhibitors and activators. Nat Rev Drug Discov 2008; 7: 168-81. https://doi.org/10.1038/nrd2467

[3] Xu Y, Feng L, Jeffrey PD, Shi Y, Morel FM. Structure and metal exchange in the cadmium carbonic anhydrase of marine diatoms. Nat Hum Behav 2008; 452: 56-61. https://doi.org/10.1038/nature06636

[4] Moya A, Tambutté S, Bertucci A, et al. Carbonic anhydrase in the scleractinian coral Stylophora pistillata characterization, localization, and role in biomineralization. J Biol Chem 2008; 283: 25475-84. https://doi.org/10.1074/jbc.M804726200

[5] Nishimori I, Onishi S, Takeuchi H, Supuran CT. The $\alpha$ and $\beta$ classes carbonic anhydrases from Helicobacter pylori as novel drug targets. Curr Pharm Des 2008; 14: 622-30. https://doi.org/10.2174/138161208783877875

[6] Švastová E, Hulíková A, Rafajová M, et al. Hypoxia activates the capacity of tumor-associated carbonic anhydrase IX to acidify extracellular pH. FEBS Lett 2004; 577: 439-45. https://doi.org/10.1016/j.febslet.2004.10.043

[7] Ebbesen P, Pettersen EO, Gorr TA, et al. Taking advantage of tumor cell adaptations to hypoxia for developing new tumor markers and treatment strategies. J Enzyme Inhib Med Chem 2009; 24: 1-39. https://doi.org/10.1080/14756360902784425

[8] Supuran CT, Scozzafava A, Casini A. Carbonic anhydrase inhibitors. Med Res Rev 2003; 23: 146-89. https://doi.org/10.1002/med.10025
Supuran CT. Carbonic anhydrases-an overview. Curr Pharm Des 2008; 14: 603-14. https://doi.org/10.2174/138161208783877884

[10] Rowlett RS. Structure and catalytic mechanism of the $\beta$ carbonic anhydrases. Biochim Biophys Acta 2010; 1804: 362-73.

https://doi.org/10.1016/j.bbapap.2009.08.002

[11] Zimmerman SA, Ferry JG, Supuran CT. Inhibition of the archaeal $\beta$-class (Cab) and $y$-class (Cam) carbonic anhydrases. Curr Top Med Chem 2007; 7: 901-8. https://doi.org/10.2174/156802607780636753

[12] Monti SM, Supuran CT, De Simone G. Anticancer carbonic anhydrase inhibitors: a patent review (2008-2013). Expert Opin Ther Pat 2013; 23: 737-49. https://doi.org/10.1517/13543776.2013.798648

[13] Venters RA, Farmer II BT, Fierke CA, Spicer LD. Characterizing the use of perdeuteration in NMR studies of large proteins: $13 \mathrm{C}, 15 \mathrm{~N}$ and $1 \mathrm{H}$ assignments of human carbonic anhydrase II. J Mol Biol 1996; 264: 1101-16. https://doi.org/10.1006/imbi.1996.0699

[14] Supuran CT. Carbonic anhydrase inhibitors: an editorial. Expert Opin Ther Pat 2013; 23: 677-9. https://doi.org/10.1517/13543776.2013.778246

[15] Supuran CT, Maresca A, Gregáň F, Remko M. Three new aromatic sulfonamide inhibitors of carbonic anhydrases I, II, IV and XII. J Enzyme Inhib Med Chem 2013; 28: 289-93. https://doi.org/10.3109/14756366.2011.649269

[16] Neri D, Supuran CT. Interfering with $\mathrm{pH}$ regulation in tumours as a therapeutic strategy. Nat Rev Drug Discov 2011; 10 : 767-77. https://doi.org/10.1038/nrd3554

[17] Thiry A, Dogne JM, Masereel B, Supuran CT. Targeting tumor-associated carbonic anhydrase IX in cancer therapy. Trends Pharmacol Sci 2006; 27: 566-73. https://doi.org/10.1016/..tips.2006.09.002

[18] Supuran CT. Carbonic anhydrase inhibitors and activators for novel therapeutic applications. Future Med Chem 2011; 3 : 1165-80.

https://doi.org/10.4155/fmc.11.69

[19] Maresca A, Temperini C, Vu H, et al. Non-Zinc Mediated Inhibition of Carbonic Anhydrases: Coumarins Are a New Class of Suicide Inhibitors\#. J Am Chem Soc 2009; 131: 3057-62.

https://doi.org/10.1021/ja809683v

[20] Maresca A, Temperini C, Pochet L, Masereel B, Scozzafava A, Supuran CT. Deciphering the mechanism of carbonic anhydrase inhibition with coumarins and thiocoumarins. $J$ Med Chem 2009; 53: 335-44.

https://doi.org/10.1021/jm901287j

[21] (a) Maresca A, Supuran CT. Coumarins incorporating hydroxy-and chloro-moieties selectively inhibit the transmembrane, tumor-associated carbonic anhydrase isoforms IX and XII over the cytosolic ones I and II. Bioorg Med Chem Lett 2010; 20: 4511-4. https://doi.org/10.1016/j.bmcl.2010.06.040

(b) Maresca A, Scozzafava A, Supuran CT. 7, 8Disubstituted-but not 6, 7-disubstituted coumarins selectively inhibit the transmembrane, tumor-associated carbonic anhydrase isoforms IX and XII over the cytosolic ones I and II in the low nanomolar/subnanomolar range. Bioorg Med Chem Lett 2010; 20: 7255-8. https://doi.org/10.1016/j.bmcl.2010.10.094

[22] Bonneau A, Maresca A, Winum JY, Supuran CT. Metronidazole-coumarin conjugates and 3-cyano-7-hydroxycoumarin act as isoform-selective carbonic anhydrase inhibitors. J Enzyme Inhib Med Chem 2013; 28: 397-401. https://doi.org/10.3109/14756366.2011.650692

[23] Touisni N, Maresca A, McDonald PC, et al. Glycosyl coumarin carbonic anhydrase IX and XII inhibitors strongly 
attenuate the growth of primary breast tumors. J Med Chem 2011; 54: 8271-7.

https://doi.org/10.1021/jm200983e

[24] Wagner J, Avvaru BS, Robbins AH, Scozzafava A, Supuran CT, McKenna R. Coumarinyl-substituted sulfonamides strongly inhibit several human carbonic anhydrase isoforms: solution and crystallographic investigations. Bioorg Med Chem 2010; 18: 4873-8.

https://doi.org/10.1016/j.bmc.2010.06.028

[25] Spicer SS, Ge ZH, Tashian RE, Hazen-Martin DJ, Schulte BA. Comparative distribution of carbonic anhydrase isozymes III and II in rodent tissues. Am J Anat 1990; 187: 55-64. https://doi.org/10.1002/aja.1001870107

[26] MJ Frisch, GW Trucks, HB Schlegel, GE Scuseria, et al. Gaussian. Inc., Wallingford CT. 2009.

[27] Dennington RD, Keith TA, Millam JM. GaussView 5.0. 8. Gaussian Inc. 2008.

[28] Parr RG, Yang W. Density Functional Theory of Atoms and Molecules Oxford Univ. Press, New York. 1989.

[29] Becke AD. Density-functional thermochemistry. III. The role of exact exchange. J Chem Phys 1993; 98: 5648-52.

https://doi.org/10.1063/1.464913
[30] Zhao Y, Truhlar DG. The M06 suite of density functionals for main group thermochemistry, thermochemical kinetics, noncovalent interactions, excited states, and transition elements: two new functionals and systematic testing of four M06-class functionals and 12 other functionals. Theor Chem Acc 2008; 120: 215-41.

https://doi.org/10.1007/s00214-007-0310-x

[31] Navarrete M, Rangel C, Corchado JC, Espinosa-Garcia J. Trapping of the $\mathrm{OH}$ radical by a-tocopherol: a theoretical study. J Phys Chem A 2005; 109: 4777-84. https://doi.org/10.1021/jp050717e

[32] Chandra AK, Uchimaru T. The $\mathrm{OH}$ bond dissociation energies of substituted phenols and proton affinities of substituted phenoxide ions: A DFT study. Int J Mol Sci 2002; 3: 407-22.

https://doi.org/10.3390/i3040407

[33] Zhang HY, Ji HF. S-H proton dissociation enthalpies of thiophenolic cation radicals: a DFT study. J Mol Struct 2003; 663: 167-74.

https://doi.org/10.1016/j.theochem.2003.08.124 